\title{
Variaciones en la composición proteica, actividades enzimáticas y bio- lógicas del veneno de la serpiente Bothrops atrox (viperidae) en rela- ción con la edad
}

\author{
Variations in the protein composition, enzymatic and biological activities in the \\ venom of Bothrops atrox snake (viperidae) in relation to age
}

\author{
O. Málaga. C. Pantigoso, Y. Morante, V. Heredia, J. Cárdenas, y A. Yarlequé*
}

\section{RESUMEN}

La serpiente Bothrops atrox, que habita en la Selva Amajónica del Perú, es responsable del mayor número de accidentes ofidicos y constituye un problema de salud públic a. Por esla razón, se ha realizado un estudio de las variaciones en la composicion y actividad del veneno en tres grupos de especimenes en cautiverio, que corresponden a juveniles de 1 y 2 años, asi como ejemplares adultos mayores de 5 años. Los venenos obtenidos fueron liofilizados para su conservación y diluidos en concentraciones iniciales de $1 \mathrm{mg} / \mathrm{ml}$ en solución salina o en el buffer apropiado.

Con estas muestras se efectuaron los análisis de concentración de proteina por 0. 0.280 nm y por el método de Lowry, delerminándose además el numero de bandas proteicas por electroforesis en gel de poliacrilamida con dodecil sulfato de sodio (PAGE-SDS). Con las mismas muestras se hicieron ensayos para medir las siguientes actividades enzimáticas: caseínolitica, amidolítica, coagulante, hialuronidasa, L- aminoácido oxidasa (LAO) y fostolipasa $A$. adicionalmente se delerminó la actividad hemorrágica y el efeclo edemático con ratones albinos.

Los resuliados mostraron que la mayor concentracion proteica $(0,938 \mathrm{mg}$ de proteina $/ \mathrm{mg}$ de veneno) asi como el número máximo de bandas proteicas ( 8 bandas) se obtuvieron con los venenos de juveniles de 2 años. Asimismo se encontró que algunas actividades enzimáticas como la amidolítica, fosfolipásica y L-aminoácido oxidasa fueron más altas en los juveniles de 2 años, además de los efectos hemorrágico y edemático. En cambio, las actividades coagulante y proteolitica sobre caseina se elevaron progresivamente con la edad de los ejemplares. Sin embargo, la enzima hialuronidasa tuvo su máximo valor en los juveniles de 1 año, decreciendo notablemente en los adullos. Es interesante señalar también que fosiolipasa $A_{2}$ en los adultos sólo tuvo una actividad de $6,4 \%$ con respecto al valor más alto encontrado en el veneno de juveniles de 2 años.

Palabras clave: Bothrops atrox, serpiente, veneno, edad, cautiverio

\section{ABSTRACT}

Bothrops atrox is the main venomous snake in the Amazonic region of Peru, because it is responsible of the majority of human ophidic accidents. For this reason. variation into chemical composition as well as enzymatic activities on this venom were studied in relation 10 age, considering 3 groups of captivity snakes: young of 1 and 2 years respectivcly as well as adult, major of 5 years. The venom obtained from the three groups was pooled, lyophilized and properly dissolved into saline solution.

Protein concentration at $280 \mathrm{~nm}$ and by Lowry's method was calculated into each venom sample. Besides, protein bands were determined by PAGE-SDS. In addition, the following enzymatic activities were determined: caseinolytic, Amidolytic on BAPNA, coagulant, hialuronidase, L-aminoacidoxidase ( $L A O)$ and losfolipase $A_{2}$. Biological effects such as hemorrhage and edema were assayed on white mice.

The results showed that high protein concentration $(0,938 \mathrm{mg}$ protein $/ \mathrm{mg}$ venom) and a bigger number of protein bands ( 8 bands) were found in the venom from young snakes ( 2 years).

Besides, amidolytic, loslolipase $A_{2}$ and $L A O$ as well as hemorrhagic and edemalic elfects were the most highest in the same samples. In contrast, caseinolytic and coagulant activities were found to increase in proportion to age. Hiaturonidase activity decreased with age instead. It was interesting to observe that the venom Irom adult snakes had only $6,4 \%$ folfolipase $A_{2}$ activity, taking into consideration that the maximum value was obtained with sample of young snakes (2 years).

Key words: Bothrops atrox, snake, venom, age, captivily.

\section{INTRODUCCIÓiN}

Las serpientes del género Bothrops habuan en una extensa región de América que abarca

\footnotetext{
Sercentario “Oswaldo Meneses". Museo de Historia Natural Laboratorio do Biologia Molecular. Facultad de Ciencias Bológicas. UNMSM. Av. Venezuela Codra. $34 \sin$. Ciudad Universitaria. dr900420unmsm.edu.pe
}

desde México hasta Argentina, habiéndose descrito en nuestro país hasta 17 especies de este género (Meneses, 1974), de las cuales la más abundante y peligrosa es Bothrops atrox, conocida como "jergón" (Carrillo e Icochea, 1995) 
El estudio de las variaciones en la composición de los venenos en relación con la edad de las serpientes tiene importancia tanto desde el punto de vista de ciencia básica como en el campo clínico. Así, Bonilla et al. (1973) han sugerido el uso de venenos de serpientes juveniles del género Crotalus horridus horridus para purificar la enzima Laminoácido oxidasa por encontrarse en proporciones significativamente mayores que en el veneno de ejemplares adultos.

Otros estudios, tanto bioquímicos como farmacológicos, en los que se han comparado venenos de serpientes adultas con los de juveniles y recién nacidas de la misma especie han demostrado que existen diferencias significativas en algunas de sus propiedades tales como letalidad, actividades enzimáticas, patrones electroforéticos y efectos locales (Gutiérrez et al., 1980; Mier and Freivogel, 1980; Lomonte et al., 1983). En este sentido, distintos trabajos muestran que, en general, los individuos recién nacidos y juveniles de la familia Crotalidae poseen venenos más letales (Minton, 1967; Fiero et al., 1972; Reid y Theakston, 1978).

Se ha reportado que muchos de los accidentes ofídicos en nuestra Amazonía son causados por especímenes recién nacidos o juveniles de Bothrops atrox, pero ellos son erróneamente atribuidos a Crotalus durissus conocida como "Cascabel" (Carrillo e Icochea, 1995). Esto se debe a las similitudes morfológicas y a que los efectos clínicos observados en los accidentes con juveniles son distintos de los causados por sus homólogos adultos, pero similares a los producidos por $\mathrm{Cro}$ talus.

Teniendo en cuenta los severos efectos locales y sistémicos que causa el envenenamiento por $B$. atrox y que estos dependerían de las variaciones en la composición del veneno de acuerdo con la edad, nos propusimos investigar dichas variaciones así como los cambios en las actividades enzimáticas y acción hemorrágica en ejemplares de diferentes edades mantenidos en cautiverio.

\section{MATERIAL Y MÉTODOS}

\section{Material Biológico}

Para el presente estudio se utilizó el veneno de tres grupos de serpientes mantenidas en cautiverio en el Serpentario "Oswaldo Meneses" del Museo de Historia Natural de la Universidad Nacional Mayor de San Marcos. Ll primer grupo estuvo conformado por cuatro especímenes juveniles de 1 año de edad y el segundo por tros ejemplares de 2 años, todos nacidos y criados en el sexpentario. El tercer grupo estuvo conformado por cuatro ejemplares adultos cuya edad promedio fue de 5 años, que procedían de los alrededores de Pucallpa-Departamento de Ucayali.

El veneno extraído por presión manual de las glándulas de cada ejemplar fue mezclado según los grupos establecidos, fue liofilizado y conservado a $-4{ }^{\circ} \mathrm{C}$. Para las pruebas se hicieron diluciones en $\mathrm{NaCl}$ al $0,9 \%$ o en el buffer apropiado, según fuera conveniente.

\section{Determinaciún de proteína}

Fue calculada midiendo la absorbancia a $280 \mathrm{~nm}$ en un espectrofotómetro Shimatzu, modelo UV-120-02. También se usó el método de Lowry et al. (1951) modificado en nuestro laboratorio (Loayza et al. 1985) empleando albúmina sérica bovina $0,1 \mathrm{mg} / \mathrm{ml}$ como estándar.

\section{Electroforesis}

El veneno de $B$. atrox de los tres grupos en estudio fue áralizado por electroforesis en gel de poliacrilamida al 7,5\% con dodecil sulfato de sodio (PAGE-SDS), en una cámara de minislab Techware, suministrando una corriente de 100 voltios durante 1 hora, de acuerdo al mélodo de Weber and Osborn (1969).

\section{Actividades enzimáticas}

Caseinolítica. Fue estimacia por el método de Kunitz (1946), modificado pu Takahashi y Oshaka (1970), utilizando caseína al 2\% en 
buffer Tris- $\mathrm{HCl} 0,2 \mathrm{M}$ pH 8,5 y $0,1 \mathrm{ml}$ de solución de veneno. La mezcla de reacción fue incubada durante 10 minutos a $37^{\circ} \mathrm{C}$, deteniéndose la reacción con la adición de ácido tricloroacético $0,44 \mathrm{M}$, y la actividad se midió por la formación de productos ácidosolubles a $280 \mathrm{~nm}$. La actividad específica fue calculada convirtiendo los valores de D. O. $280 \mathrm{~nm}$ a $\mu \mathrm{g}$ de L-tirosina determinada por el método de Lowry et al. (1951) y expresada en unidades de actividad / mg de proteína.

Amidolítica. La mezcla de reacción conteniendo $2 \mathrm{ml}$ del sustrato benzoil-arginilp-nitroanilida (BAPNA) $9 \times 10^{-4} \mathrm{M}$ en buffer Tris-HCl 0,05 M pH 8,1 y 0,1 ml de veneno, fue incubada a $37^{\circ} \mathrm{C}$ por 15 minutos. La reacción se detuvo con $0,6 \mathrm{ml}$ de ácido acético al $60 \%$ determinándose la actividad a $405 \mathrm{~nm}$ de la p-nitroanilina liberada. La actividad específica se expresó en $\mu$ moles de sustrato hidrolizado / minuto / mg de proteína (Erlanger et al., 1961).

Coagulante. La actividad coagulante fue medida según el método de Oshima et al. (1969) empleando como sustrato fibrinógeno bovino $5 \mathrm{mg} / \mathrm{ml}$ en buffer fosfato salino (PBS) $0,02 \mathrm{M}$ pH 7,4. La mezcla de reacción fue preincubada a $37^{\circ} \mathrm{C}$ por 10 minutos y luego de adicionar $0,1 \mathrm{ml}$ de la solución de veneno, se midió el tiempo de coagulación. La actividad específica fue expresada como unidades de actividad / mg de proteína.

Hialuronidasa. Fue determinada usando como sustrato ácido hialurónico $\mid \mathrm{mg} / \mathrm{ml}$ en buffer acetato de sodio $0,2 \mathrm{M}$ pH 6.0, añadiéndose $0,1 \mathrm{ml}$ de la solución de veneno (100 mg). La mezcla de reacción se incubó por 15 minutos a $37{ }^{\circ} \mathrm{C}$ siendo la actividad cuantificada turbidimétricamente a $400 \mathrm{~nm}$ luego de adicionar el reactivo de Cetil Trimetil Amonio $2,5 \%$ en $\mathrm{NaOH} 2 \%$ (Di-Ferrate, 1956). El descenso de la turbidez al $50 \%$ del valor inicial se consideró como una unidad de actividad. La actividad especifica fue expresada en Unidades Di-Ferrate / mg de proteína.

L-aminoácido oxidasa (LAO). Se empleó como sustrato L-Leucina al $0,1 \%$ en buffer Tris-Imidazol $0.2 \mathrm{M}$ pH 7,6 que contenía $0,0065 \%$ de o-Dianizidina. La mezcla de reacción conteniendo $2,9 \mathrm{ml}$ de sustrato y $0,01 \mathrm{ml}$ de peroxidasa comercial al $0,001 \%$, fue preincubada a $37^{\circ} \mathrm{C}$ por 5 minutos, y luego se añadió $100 \mu \mathrm{l}$ de cada veneno, registrándose el incremento en la D.O. a $436 \mathrm{~nm}$ (Sánchez and Magalhaes, 1991).

Fosfolipasa $\mathbf{A}_{2}$. Se empleó como sustrato 1,5 $\mathrm{ml}$ de una emulsión de yema de huevo al $45 \%$ en buffer Tris-HCl $10 \mathrm{mM}$ pH 7,5. Luego de adicionar $100 \mu \mathrm{l}$ de cada veneno se incubó por 10 minutos a $37^{\circ} \mathrm{C}$. Después, las mezclas fueron sometidas en un baño de temperatura a $100^{\circ} \mathrm{C}$, midiéndose el retardo en el tiempo de coagulación de la yema de huevo. La actividad específicil fue expresada como el retardo en el tiempo de coagulación / minuto / mg de proteína (Vidal et al., 1970).

\section{EFECTO HEMORRÁGICO}

Se empleó el método de Kondo et al. (1960) con algunas modificaciones. Grupos de 4 ratones albinos de $18-20 \mathrm{~g}$ fucron inoculados por vía intradérmica con dosis de $0,8,1,0 \mathrm{y}$ $1,25 \mu \mathrm{g}$ de cada uno de los venenos en un volumen de $0,1 \mathrm{ml}$. A las 2 horas los animales fueron sacrificados por inhalación de éter etílico; la piel fue removida y se midió el área de la mancha hemorrágica. Como control se inocularon ratones albinos por vía intradérmica con $0,1 \mathrm{ml}$ de buffer fosfato salino $\mathrm{pH} \mathrm{7,4.} \mathrm{La}$ actividad hemorrágica se expresó como la Dosis Hemorrígica Mínima (DHM), que es la cantidad de veneno que induce a la formación de un área hemorrágica de $10 \mathrm{~mm}$ de diámetro. 
Asimismo, la PAGE-SDS a pH 7.0 reveló 4,8 y 6 bandas proteicas definidas para los ejemplares de I año, 2 años y adultos, respectivamente. Igualmente se pueden observar 2 bandas proteicas comunes en todos los casos siendo una de ellas con pesos moleculares cercanos a $66 \mathrm{kda}$ y las otras con pesos moleculares alrededor de 14,3 kda. (Fig. 1)

2. Actividades Amidolítica y Coagulante. Los datos encontrados en la evaluación de la actividad amidolítica sobre BAPNA mostraron que el veneno de especímenes de 2 años tuvo el máximo valor correspondiente a $0,922 \mathrm{U} / \mathrm{mg}$ y el más bajo correspondió a los cspecímenes de 1 año con 0,268 U/mg. En cuanto a la acción coagulante sobre fibrinógeno bovino registramos la máxima actividad de 37,35 X $10^{-2} \mathrm{U} / \mathrm{mg}$ de proteína para especímenes adultos, mientras que los valores encontradns para los ejemplares de 1 y de 2 :ños fueron menors y muy cercanos entre si (Tabla 2).

3. Acción Proteolítica, Hemorrágica y Fosfolipásica. La capacidad para degradar proteínas de cada una de las muestras investigadas se observa en la Tabla 3. Así, puede apreciarse que la actividad proteolítica se incrementa en relación con lá edad hasta alcanzar un valor máximo de $59,57 \mathrm{U} / \mathrm{n} g$ de proteina en ausencia de calcio y de 100,14 U/mg con la adición de $\mathrm{Ca}^{2+} 10 \mathrm{mM}$ en ejemplares acultos.

Con relación a la actividad de Fosfolipasa $A_{2}$ es significativa nente clevada en los juveniles de 2 años con un valor de 26,92 U/ $\mathrm{mg}$ de proteína, notándose que en el veneno de los ejemplares adultos esta actividad es de $\tan$ solo 1,72U/mg (Tabla 3).

\section{TABLA 2. ACTIVIDAD AMIDOLITICA Y COAGULANTE EN EL VENENO DE LA SERPIENTE Bothrop: alrox}

\begin{tabular}{c|cr}
\hline $\begin{array}{c}\text { EDAD PROMEDIO } \\
\text { (años) }\end{array}$ & \multicolumn{2}{|c}{$\begin{array}{c}\text { ACTIVIDADESPECIFICA } \\
\text { (U/mg prot.) }\end{array}$} \\
\hline & AMIDOLITICA & COAGULANTE \\
1 & 0,268 & $23,59 \times 10^{-2}$ \\
2 & 0,922 & $25,61 \times 10^{-3}$ \\
5 & 0,332 & $37,55 \times 10^{-2}$ \\
\hline
\end{tabular}

TABLA 3. ACTIVIDAD PROTEOLITICA Y FOSFOLIPÁSICA A EN EL VENENO DE LA SERPIENTE Bothrops atrox

\begin{tabular}{c|lrr}
\hline $\begin{array}{c}\text { EDAD PROMEDIO } \\
\text { (años) }\end{array}$ & \multicolumn{3}{|l}{$\begin{array}{l}\text { ACTIVIDAD ESPECIFICA(U/migrot.) } \\
\text { CASEINOLITICA }\end{array}$} \\
& s/ $\mathrm{Ca}^{2+}$ & $\mathrm{c} / \mathrm{Ca}^{2+}$ & \\
\hline 1 & 38,61 & 65,89 & 10.32 \\
2 & 42,28 & 71,17 & 26,92 \\
5 & 59,71 & 100,14 & 1,72 \\
\hline
\end{tabular}


En cuanto a la actividad hemorrágica, el veneno de serpientes de 2 años de edad produce la mayor actividad al inocular 0,8 , 1,0 y $1,25 \mathrm{mg}$ de veneno respectivamente, correspondiendo la DHM a $0,9 \mathrm{mg}$; con esta misma cantidad no fue posible determinar el área hemorrágica con nitidez al inocular los venenos de 1 año y adultos.

\section{Hialuronidasa y L-aminoácido oxidasa.}

Los valores de las actividades para estas enzimas se observan en la Tabla 4. La actividad de hialuronidasa más elevada $(13,40 \mathrm{U} / \mathrm{mg})$ fue registrada en los ejemplares juveniles de un año y esta desciende con la edad hasta un valor de 6,47 en los ejemplares adultos, es decir la actividad específica se reduce a un $50 \%$ aproximadamente. En contraste, la actividad de $\mathrm{LAO}$ en juveniles de 2 años tuvo el máximo valor de 102,50 U/mg observándose que el veneno de los ejemplares adultos mantienen el $76 \%$ aprox. de la máxima actividad registrada.

5. Efecto Edemático. Los valores equivalentes a las dosis edemáticas mínimas (DEM) encontrados con los tres tipos de venenos se indican en la Tabla 5. Como puede observarse el veneno de juveniles de 2 años, produjo cl máximo efecto edemático con un valor de $2,65 \mu \mathrm{g}$, mientras que en los adultos este efecto se redujo aproximadamente 14 veces.

\section{DISCUSIÓN}

La posibilidad de evaluar las variaciones en la composición química y por snde la acción tóxica de un veneno, tiene especial importancia no solo porque ello permite acercarnos al conocimiento de la físiología del ofidio sino que principalmente nos va a guiar en el apropiado

\section{TABLA 4. ACTIVIDAD DE HIALURONIDASA Y !--AMINOÁCIDO OXIDASA EN EL VENENO DE LA SERPIENTE Bothrops atrox}

\begin{tabular}{c|cc}
\hline \multirow{2}{*}{$\begin{array}{c}\text { EDAD PROMEDIO } \\
\text { (años) }\end{array}$} & \multicolumn{2}{|c}{$\begin{array}{c}\text { ACTIVIDAD ESPECIFICA (U/mg prol.) } \\
\text { HIALURONIDASA }\end{array}$} \\
\hline 1 & 13,40 & $\begin{array}{c}\text { L-AMINOACIDO } \\
\text { OXIDASA } \times 10^{-4}\end{array}$ \\
\hline 2 & 9,80 & 58,67 \\
5 & 6,47 & 102,50 \\
& & 75,26 \\
\hline
\end{tabular}

TABLA 5. DOSIS EDEMÁTICA MÍNIMA (DEM) DEL VENENO DE $B$. atrox

\begin{tabular}{c|c}
\hline $\begin{array}{c}\text { EDAD PROMEDIO } \\
\text { (años) }\end{array}$ & $\begin{array}{c}\text { DEM } \\
(\mu \mathrm{g})\end{array}$ \\
\hline 1 & $25.49 \pm 0,275$ \\
2 & $2,65 \pm 0,275$ \\
5 & $39,32 \pm 2,694$ \\
\hline
\end{tabular}

* Para determinar la DEM se emplcaron grupos de cuatro ratones para cada dosis de veneno ensayada ( \pm D.S. $n=4$ ) 
tratamiento contra su mordedura. A estos factores podemos adicionar la necesidad de vencer algunos conceptos folclóricos que usualmente tiene el poblador de la selva en torno a las serpientes y en este caso específico, existe una confusión muy difundida por la que se considera a los especímenes juveniles de $B$ atrox como ejemplares de la serpiente cascabel Crotalus durissus terrificus, especie que hasta la fecha sólo ha sido encontrada en la Selva de Sandia-Puno, limítrofe con Bolivia.

Es evidente que para llevar a cabo un estudio de este tipo se requiere el continuo seguimiento de los ejemplares en el serpentario, y en este caso la disponibilidad de ejemplares nacidos y criados en cautiverio ha facilitado nuestro trabajo.

Varios hechos interesantes podemos deducir de los resultados encontrados; así tenemos que la cuantificación de proteína en el veneno de $B$. atrox (Tabla I) señala un incremento de $24,6 \%$ en especímenes de dos años con relación a los juveniles de 1 año, lo que equivale a decir que el veneno de juveniles ( 1 año) contiene sólo 70,7\% de proteína mientras que en los de dos años, así como en los adultos los porcentajes son muy cercanos entre sí, correspondiendo a 93,8 y $93,0 \%$ respectivamente. Estos valores nos indican una óptima concentración de proteína en condiciones de cautiverio puesto que otro reportes muestran valores menores en venenos de adultos procedentes de especímenes recién capturados (Heredia et al., 1982; Loayza et al., 1985). En relación con ello, es también importante recalcar la máxima producción de proteína de veneno en los juveniles de 2 años así como el número de bandas electroforéticas obtenidas que fue de 8 . Esto sugiere una modificación en algunas proteínas en función con el alimento según la edad hecho que concuerda con lo reportado por Chávez, et al 1992, en la especie B. asper de Centro América.
En cuanto a las acrividucles de las enzimas proteolíticas tales como caseinolítica y coagulante, estas se incrementan con ia edad. En el caso de la aclividad sobre caseína, el incremento en el adulto con relación a venenos de juveniles de l año es de $35,3 \%$ y este porcentaje se mantiene cuando se adiciona $\mathrm{Ca} 2+(10 \mathrm{mM}$ ), como activador (Pantigoso et al., 1996). Asimismo, la actividad coaguîante se incrementó en un porcentaje de $37,2 \%$ con relación a la actividad del veneno de juveniles de I año (Tabla 2).

Resultados similares a los nuestros han sido reportados para veneno de juveniles y adultos de $C$. horridus horridus y de $C$. durissus durissus por Bonilla et al. (1973) y Lomonte et al. (1983) respectivamente. Sin embargo, Gutiérrez et al. (1980) al trabajar con la especie $B$. asper encontraron que la actividad proteolítica es más alta en recién nacidos que en adultos. Este último hecho tiene especial significado puesto que se considera que $B$ asper de Centroamérica es un pariente muy cercano a la $B$. atrox sudamericana, empero los datos mostrados indican claras diferencias en la actividad de ambos venenos.

El hecho de que las actividades proteolítica y coagulante se incrementen es evidencia de que los efectos a nivel tisular y sistémico atribuidos a estas enzimas son más potentes con la edad de modo que la aparición de edema, la hidrólisis de proteínas plasmáticas y la conversión de fibrinógeno en fibrina serán efectos clínicos muy notables en accidentes producidos por serpientes adultas. Asimismo. la adición de calcio determinaría una mayor actividad proteolítica, lo que demuestra claramente la ineficacia de productos comoel gluconato de calcio usados en algunos lugares como parte de la terapia antivenenosa (Yarlequé, 2000).

Por otro lado, en la Tabla 3 se puede apreciar una óptima actividad de la enzima fosfolipasa $\mathrm{A}_{2}$ en especímenes de 2 años, así como de la L-aminoácido oxidasa (Tabla 4) y 
tratamiento contra su mordedura. A estos factores podemos adicionar la necesidad de vencer algunos conceptos folclóricos que usualmente tiene el poblador de la selva en torno a las serpientes y en este caso específico, existe una confusión muy difundida por la que se considera a los especímenes juveniles de $B$. atrox como ejemplares de la serpiente cascabel Crotalus durissus terrificus, especie que hasta la fecha sólo ha sido encontrada en la Selva de Sandia-Puno, limítrofe con Bolivia.

Es evidente que para llevar a cabo un estudio de este tipo se requiere el continuo seguimiento de los ejemplares en el serpentario, y en este caso la disponibilidad de ejemplares nacidos y criados en cautiverio ha facilitado nuestro trabajo.

Varios hechos interesantes podemos deducir de los resultados encontrados; así tenemos que la cuantificación de proteína en el veneno de $B$. atrox (Tabla I) señala un incremento de $24,6 \%$ en especímenes de dos años con relación a los juveniles de 1 año, lo que equivale a decir que el veneno de juveniles ( I año) contiene sólo 70,7\% de proteína mientras que en los de dos años, así como en los adultos los porcentajes son muy cercanos entre sí, correspondiendo a 93,8 y $93,0 \%$ respectivamente. Estos valores nos indican una óptima concentración de proteína en condiciones de cautiverio puesto que otro reportes muestran valores menores en venenos de adultos procedentes de especímenes recién capturados (Heredia et al., 1982; Loayza et at., 1985). En relación con ello, es también importante recalcar la máxima producción de proteína de veneno en los juveniles de 2 años así como el número de bandas electroforéticas obtenidas que fue de 8 . Esto sugiere una modificación en alyunas proteínas en función con el alimento según la edad hecho que concuerda con lo reportado por Chávez, et al 1992, en la especie B. asper de Centro América.
En cuanto a las acliviclacles de las enzimas proteolíticas tales como caseinolítica y coagulante, estas se incrementan con la edad En el caso de la actividad sobre caseína, el incremento en el adulto con relación a venenos de juveniles de 1 año es de $35,3 \%$ y este porcentaje se mantiene cuando se adiciona $\mathrm{Ca} 2+(10 \mathrm{mM})$, como activador (Pantigoso et al., 1996). Asimismo, la actividad coaguiante se incrementó en un porcentaje de $37.2 \%$ con relación a la actividad del veneno de juveniles de I año (Tabla 2).

Resultados similares a los nuestros han sido reportados para veneno de juveniles y adultos de $C$. horridus horridus y de $C$. durissus durissus por Bonilla et al. (1973) y Lomonte et al. (1983) respectivamente. Sin embargo, Gutiérrez et al. (1980) al trabajar con la especie $B$. asper encontraron que la actividad proteolítica es más alta en recién nacidos que en adultos. Este último hecho tiene especial significado puesto que se considera que $B$. asper de Centroamérica es un pariente muy cercano a la $B$. atrox sudamericana, empero los datos mostrados indican claras diferencias en la actividad de ambos venenos.

El hecho de que las actividades proteolítica y coagulante se incrementen es evidencia de que los efectos a nivel tisular y sistémico atribuidos a estas enzimas son más potentes con la edad de modo que la aparición de edema, la hidrólisis de proteínas plasmáticas y la conversión de fibrinógeno en fibrina serán efectos clínicos muy notables en accidentes producidos por serpientes adultas. Asimismo. la adición de calcio determinaría una mayor actividad proteolítica, lo que demuestra claramente la ineficacia de productos comoel gluconato de calcio usados en algunos lugares como parte de la terapia antivenenosa (Yarlequé, 2000).

Por otro lado, en la Tabla 3 se puede apreciar una óptima actividad de la enzima fosfolipasa $A$, en especímenes de 2 años, así como de la L-aminoácido oxidasa (Tabla 4) y 
la actividad amidolítica (Tabla 2). Es muy interesante este hallazgo en relación con fosfolipasa $A_{2}$, pues siendo su máxima actividad de $26,92 \mathrm{U} / \mathrm{mg}$ de proteína, en el adulto se registró $1,72 \mathrm{U} / \mathrm{mg}$ lo que equivale a $6,38 \%$ del valor máximo. Esto podría deberse a la síntesis de un péptido inhibidor de fosfolipasa detectado en algunos venenos cuya máxima concentración estaría en los especímenes adultos; péptidos de esta chase son inactivados por calentamiento a $80^{\circ} \mathrm{C}$ o por elevación del pH (Vidal et al., 1972). Por lo demás, la elevada actividad amidolítica en los juveniles de 2 años, la cual básicamente corresponde a la similar a trombina (proteína coagulante), podría estar asociada en este caso a la acción kininogenásica que produce efecto hipotensor (Magalhaes et al., 1981) En relación con la acción de L-aminoácido oxidasa y la demostración de su actividad antibacteriana en este veneno (Yarlequé et al., 1997), es evidente que los especímenes juveniles tendrían una mayor capacidad para neutralizar la flora microbiana de la presa empleando esta proteína.

Similarmente hemos encontrado qie la DHM en los ejemplares de dos años fue de $0,9 \mu \mathrm{g}$ sin embargo al utilizarse esta misma cantidad de protuina con los venenos de 1 año y de adultos respectivamente, se obtuvo una pequeña área hemorrágica cuyo diámetro fue menor a $1 \mathrm{~cm}$, indicando que en ambos casos se requería incrementar la cantidad de proteína para obtener las DHM, correspondientes. Minton (1967) encontró en el veneno de Crolalus horridus atricaudatus que la actividad hemorrágica aumentaba con la edad, mientras que en la especie Bothrops asper Gutiérrez et al. (1980) reportaron que el veneno de recién nacidos es más hemorrágico que el de adultos. Por su parte Chávez, el al. (1992), demostraron que la DHM para recién nacidos de $B$. asper fue de $0,95 \pm 0,06 \mathrm{mg}$, siendo este valor muy semejante al encontrado por nosotros en ejemplares juveniles de 2 años.
Finalmente, la Tabla 4, indica el notable descenso de la actividad hialuronidásica al aumentar la edad del espécimen puesto que el valor registrado en el adulto apenas es cercano al 50\% de juveniles de $l$ año. Esto indudablemente estaría relacionado con e] requerimiento del factor difusor (hialuronidasa) el cual debe ser mayor en los especímenes más jóvenes por la menor cantidad de veneno que inyectan durante la mordedura. Además hay que tener en cuenta la mayor complejidad del veneno de los adultos, que aseguraría su acción biológica sin que sea significativamente necesaria la presencia de esta enzima

En este mismo sentido, debemos destacar que la actividad edemática es muy potente en los juveniles de 2 años y se reduce notablemente en los adultos, guardando relación cor la actividad fosfolipásica, la cual esta notablemente incrementada en los juveniles de 2 años.

En conclusión, podemos decir que las variaciones que presenta el veneno de $B$. alrox de acuerdo con la edad, probablemente obedecen a mecanismos de regulación en la síntesis de las proteínas los cuales aún son poco conocidos.

Estos mecanismos estarían asociados a efectos hormonales que influyen adicionalmente en el crecimiento, frecuencia de muda y otros efectos fisiológicos que se hacen mas eviduntes en los juveniles que están en plena etapa de crecimiento

\section{AGRADECIMIENTOS}

Los autores agradecen al Consejo Superior de Investigaciones, a la Embajada Británica y a la International Foundalion for Science (IFS) por el apoyo que brindaron a la presente investigacion. 


\section{LITERATURA CITADA}

Bonilla, C., H. Faith and S. Minton Jr. 1973. L-aminoacid oxidase, phosphodiesterase, total protein and other properties of juvenile timber rattlesnake (C.h. horridus) venom at different stages of growth. Toxicon 11:301.

Carrillo, N. y J. Icochea. 1995. Lista taxonómica de los reptiles vivientes del Perú, Publicaciones del Museo de Historia Natural, UNMSM, Serie A, N. ${ }^{\circ}$ 49, 27 pp.

Chávez, F., J. Gutiérrez and F. Brenes. 1992. Pathological and biochemical changes induced in mice after intramuscular injection of venom from newborn specimens of the snake Bothrops asper (terciopelo). Toxicon 30 (9): 1099-1109.

Di-Ferrate, N. 1956. Turbidimetric measurement of acid mucopolisacharides and hialuronidase activity. J. Biol: Chem. 220: 303 .

Erlanger, B.; N. Kokowski and Cohen. 1961. The preparation and properties of the new chromogenic substrates of trypsin. Arch. Biochem. Biophys (95) : 271

Fiero, M., M. Seifert; T. Weaver and C Bonilla. 1972. Comparative study of juvenile and adult prairie rattlesnake ( $\mathrm{Cro}$ talus viridis viridis) venoms. Toxicon 10,81 .

Gutiérrez, J., F. Chávez y R. Bolaños. 1980. Estudio comparativo de venenos de ejemplares recién nacidos y adultos de Bothrops asper. Rvsta. Biol. Trop. 28 : 341

Heredia, V., S. Campos, y A. Yarlequé. 1982. Actividad de una 5' Nucleotidasa en el veneno de la serpiente Bothrops atrox
(L.) "jergón”. Acta Científica Venezolana. 33: 333-337.

Kondo, H., S. Kondo, I. Ibezawa, R. Murota and A. Ohsaka. 1960. Studies of the quantitative method for the determinative of hemorrhagic activity of habu snake venom. Jap. J. Med. Sci. Biol. 13,43 .

Kunitz, M. 1946. Crystalline soybean trypsin inhibitor II. General properties. J. Gen. Physiol. 30: 291-310.

Loayza, S., Y. Morante, S. Campos y A. Yarlequé. 1985. Enzimas proteolíticas en los venenos de las serpientes peruanas Lachesis muta y Bothrops atrox. Boletin de la Sociedad Química del Perú. Vol. LII. (3) : 151-163

Lomonte, B., J. Gene, J. Gutierrez y I. Cerdas I. 1983. Estudio comparativo de los venenos de serpiente Cascabel (Crotalus durissus durissus) de ejemplares adultos y recién nacidos. Toxicon 21 (3): 379-384

Lowry, O., H. Rosebrough, A. Farr and R. Randall. 1951. Protein measurement with the pholinphenol (reagent) J. Biol. Chem. 193: 265-275.

Magalhaes, A., G. Oliveita and C. Diniz. 1981 Purification and partial characterization of a thrombin-like enzyme from the venom of the bushmaster snake, Lachesis muta noctivaga. Toxicon 19 , 279-294.

Meier, J. and T. Freivogei. 1980. Comparative studies on the venoms of the ferde-lance (Bothrops atrox), carpet viper (Echis carinatus) and spitting cobra (Naja nigricollis) snakes at different ages. Toxicon 18,661. 
Meneses, O. 1974. Los Animales Venenosos y sus Peligros. Instituto de Salud Pública, Lima-Perú. Publicación N. ${ }^{\circ}$, pp. 3-14.

Minton, S. Jr. 1967. Observations of toxicity and antigenic make up of venoms from juvenile snakes. En.: Animal Toxins, p. 211 (Russel F. E. y Saunders P. Eds.). Oxford. Pergamon Press.

Oshima, I., T. Sato-Ohmori and T. Suzuky. 1969. Proteinase arginin ester hidrolase and kinin releasing enzyme snake venoms. Toxicon $7: 229-233$.

Pantigoso, C., E. Escobar, O. Málaga y A.. Yarlequé. 1996. Aislamiento y algunas propiedades de la Atroxina, una proteinasa del veneno de la serpiente peruana Bothrops atrox "jergón". Acta Científica Venezolana. 47(1): 67-73.

Reid, H. and R. Theakston. 1978. Changes in coagulation effects by venoms of $\mathrm{CrO}^{-}$ talus atrox as snakes age. Am. J. Tirop. Med. Hyg. 27, 1053.

Sanchez, E. and A. Magalhaes. 1991. Purification and partial characterization of an L-aminoacid oxidase from bushmaster snake (Surucucu Pico de Jaca) Lachesis muta muta venom. Brazilian J. Med. Biol. Res. 24 : 249-260.

Takahashi, T. And A. Ohsaka. 1970. Purification and characterization of proteinase in the venom of Trimeresurus flavoviridis. Complet. Separation of the enzymes from hemorrhagic activity. Biochem. Biophys. Acta 198 (2): 293. 307.

Vidal, J., P. Caltanes and A. Stoppani. 1972. Some characteristic properties on phospholipases A from Bothrops neuwedii venom. Arch. Biochem. Biophys. 151 168.

Weber, K. and Osborn, M. 1969. The reability of molecular weight determinations by dodecil sulfate polyacrilamide gel electrophoresis. J. Biol. Chem. 244: 44064412.

Yamakawa, M., Nosaki, M. and Hokama, Z. 1976. Fractionation of sakishima-habu (Trimererusus elegans) venom, and lethal, hemorrhagic and edemaforming activities of the fractions. In: Animal, Plant, and Microbial toxins, Vol. 1, Biochemistry, eds., A., Ohsaka, K. Hayashi and Y. Sawai. Plenum Press, New York.

Yarlequé, A., J. Cárdenas, E. Escobar and S. Gutiérrez. 1997. Some biochemical properties and antibacterial action of a L-amino acid oxidase from Peruvian snake venoms. Toxicon, Oxford, Edit. Pergamon Press, 35 (4) : 489.

Yarlequé, A. 2000. Las serpientes peruanas y sus venenos. Fondo Editorial de la UNMSM, 78 pp. 